\title{
Phytochemical composition of Capsicum frutescens and its effect on body weight and carcass yield of Cobb500 broilers
}

\author{
Sebulime Peregrine ${ }^{1^{*}}$, Ocaido Michael ${ }^{1}$ and Okello Samuel ${ }^{2}$ \\ ${ }^{1}$ Department of Wildlife and Aquatic Animal Resources, College of Veterinary Medicine and Biosecurity, Makerere \\ University, Kampala, Uganda. \\ ${ }^{2}$ Department of Livestock Industrial Resources, College of Veterinary Medicine Animal Resources and Biosecurity, \\ Makerere University, Kampala, Uganda
}

Received 24 January, 2021; Accepted 10 May, 2021

\begin{abstract}
This study aimed to establish phytochemical composition and determining the effect of Capsicum frutescens powder on body weight and carcass yield of Cobb500 broilers. Four hundred and fifty broilers at 35 days were randomly assigned to treatments defined by three dietary inclusion levels $(1.1,2.2,4.4 \%)$ of $C$. frutescens powder for each of the three durations (13 days, 19 days, 24 days) prior to 59 days of age. A control group received only the basal finisher diet. Each treatment group had 15 birds replicated thrice. The phytochemicals detected in $C$. frutescens powder included flavonoids, phenols (588 mg GAE/100g), alkaloids (6.8\%), and saponins (23.5\%). Further, only diets formulated with $2.2 \%$ inclusion level and provided for 19 days increased body weight $(1258 \mathrm{~g}$, $p=0.03)$, carcass weight $(786 \mathrm{~g}, p=0.03)$ by 14 and $15 \%$ respectively relative to the control. The results of this study highlight that $C$. frutescens has several beneficial phytochemicals for improving broiler production and that an inclusion level of $2.2 \%$ in finisher diets for 19 days is acceptable since it has capacity to improve body weight and carcass yield of Cobb500 broilers.
\end{abstract}

Key words: Alkaloids, chicken, body weight, phenols, carcass yield, internal organs.

\section{INTRODUCTION}

Chicken meat is considered one of the major sources of animal protein worldwide (Muaz et al., 2018). For long, antibiotics have been used as in-feed growth promoters in the chicken industry but the increase in antibiotic resistance which is a key global threat to animal and human health has prompted the search for alternatives to antibiotics for use as growth promoters in the livestock industry (FAO, 2019; Roth et al., 2019). The most common alternatives to antibiotics include: probiotics, prebiotics, synbiotics, metals, hyperimmune egg antibodies, organic acids, antimicrobial peptides, bacteriophages, clay, nanoparticles and phytochemicals (Gaddet et al., 2017). Among these alternatives, phytochemicals are probably the most diverse and have been screened especially from herbs and spices including oregano, thyme, clove, cinnamon, ginger, peppermint, garlic, black pepper and red pepper (Puvaca et al., 2015; Borgohain et al., 2017; Mahanta et al., 2017).

Several herbs and spices are known to contain

${ }^{*}$ Corresponding author. E-mail: psebulime@covab.mak.ac.ug. Tel: +256782498502.

Author(s) agree that this article remain permanently open access under the terms of the Creative Commons Attribution License 4.0 International License 
multiple phytochemicals like phenols, alkaloids, saponins and coumarins whose beneficial effects in livestock include: stimulation of immune system, reduction of oxidative stress, maintenance of gut integrity, promotion of beneficial bacterial growth and reduction of negative consequences of inflammation caused by enteric infections (Lillehoj et al., 2018). Specifically, capsicums are known to contain phytochemicals that can enhance resistance to enteric diseases such as coccidiosis and necrotic enteritis (Lillehoj et al., 2018). However, even though capsicums are one of the spices widely available and easily accessible in Uganda, their use as feed additives to improve growth of broilers has not yet been adopted mainly due to the challenge of absence of local information on the appropriate inclusion levels and duration of feeding. This study, therefore, provides important knowledge on phytochemical properties of Capsicum frutescens powder and its effect at various inclusion levels in feed on body weight and carcass yield of broilers under local farm settings.

\section{MATERIALS AND METHODS}

\section{Phytochemical analysis of C. frutescens}

\section{Qualitative analysis for particular phytochemicals}

Qualitative determination was done for the following phytochemicals: saponins, alkaloids, and flavonoids, following protocols described by Raffia et al. (2010).

\section{Saponins}

A dilute solution of the ethanol extract $(2 \mathrm{ml})$ was placed in a test tube and shaken for $15 \mathrm{~min}$. The formation of a form (soapy like) column of about $2 \mathrm{~cm}$ above liquid level in the test tube indicated the presence of saponins.

\section{Alkaloids}

The ether extract $(15 \mathrm{ml})$ was dissolved in $10 \% \mathrm{v} / \mathrm{v}$ Hydrochloric acid $(10 \mathrm{~mL})$ and the alkaloids were precipitated from the aqueous solution as bases with the help of $10 \% \mathrm{v} / \mathrm{v}$ ammonia solution $(10 \mathrm{ml})$. The ether solution was evaporated to dryness and to it, added hydrochloric acid solution $(1.5 \mathrm{ml})$. The acidic solution was divided into three portions each $0.5 \mathrm{ml}$. To one of the three acidic solutions were added 2-3 drops of Mayer's reagent. The formation of opalescence or a yellowish-white precipitate confirmed the presence of alkaloid salts.

\section{Flavonoids}

Ethanol extract $(25 \mathrm{ml})$ was mixed with $10 \% \mathrm{v} / \mathrm{v}$ hydrochloric acid $(15 \mathrm{ml})$ and refluxed for $30 \mathrm{~min}$. The solution was cooled and extracted with diethyl ether $(36 \mathrm{ml})$ in portions of $12 \mathrm{ml}$ each. The ether extract was dehydrated using anhydrous sodium sulphate. The residue obtained by evaporating ether extract $(5 \mathrm{ml})$ was heated in $50 \%$ aqueous $(2 \mathrm{~mL}$ ) and metallic magnesium $(0.5 \mathrm{~g})$ and concentrate Hydrochloric acid (5 drops) were added. The formation of a red or orange solution indicated the presence of flavonoids (Shibata's reaction)

\section{Quantitative analysis of selected phytochemicals}

Quantitative determination was undertaken for the following phytochemical compounds: phenols, alkaloids, flavonoids and saponins following procedures described by Raffia et al. (2010).

\section{Total phenols}

Total phenolic compounds were determined as garlic acid equivalent (mgGAE/g) using Folin- Ciocalteu reagent standard method as described by Brand-Willias et al. (1995) and Park et al. (2015). A total of $100 \mathrm{mg}$ of plant samples were introduced into test tubes and $10 \mathrm{ml}$ of $50 \%$ methanol were added into two portions of $5 \mathrm{ml}$ each. The sample extractions were by manual shaking for 30 and $40 \mathrm{~min}$, respectively. After each extraction, sample extract was kept at $-20^{\circ} \mathrm{C}$ for $10 \mathrm{~min}$ and thereafter centrifuged at $300 \mathrm{rpm}$ for $10 \mathrm{~min}$. The extracts were decanted into a test tube. $5.0 \mathrm{ml}$ of Folin-Ciocalteu reagent $(2 \mathrm{~N})$ was diluted with $5 \mathrm{ml}$ of distilled water. $0.1 \mathrm{ml}$ of each of the sample was diluted with $0.4 \mathrm{ml}$ distilled water and Folin-Ciocalteu reagent $(0.25 \mathrm{ml})$. $1.25 \mathrm{ml}$ of $20 \%$ sodium carbonate was added to each sample and shaken with the help of vortex. The tubes were vortexed for 15 min and then allowed to stand for $35 \mathrm{~min}$. The absorbance was measured using a spectrophotometer (Spectro UV-VIS AUTO PC Scanning Spectrophotometer; Labomed Inc, Los Angeles, CA USA) at $725 \mathrm{~nm}$.

\section{Alkaloids}

A sample weighing $5 \mathrm{~g}$ was placed into a $250 \mathrm{ml}$ beaker and 200 $\mathrm{ml}$ of $10 \%$ acetic acid in ethanol was added and covered and allowed to stand for $4 \mathrm{~h}$. The mixture was filtered and the extract was concentrated on a water bath to one-quarter of the original volume. Concentrated ammonium hydroxide was added dropwise to the extract until the precipitation was complete. The whole solution was allowed to settle, filtered and the precipitate was collected. The residue was the alkaloid, which was dried and weighed.

\section{Saponins}

The samples were ground and $5 \mathrm{~g}$ of each were put into a conical flask and $100 \mathrm{~cm} 3$ of $20 \%$ aqueous ethanol were added. The samples were heated over a hot water bath for $4 \mathrm{~h}$ with continuous stirring at about $55^{\circ} \mathrm{C}$. The mixture was filtered and the residue reextracted with another $200 \mathrm{ml} 20 \%$ ethanol. The combined extracts were reduced to $40 \mathrm{ml}$ over water bath at about $90^{\circ} \mathrm{C}$. The concentrate was transferred into a $250 \mathrm{ml}$ separating funnel and $20 \mathrm{ml}$ of diethyl ether were added and shaken vigorously. The aqueous layer was recovered while the ether layer was discarded. The purification process was repeated. $60 \mathrm{ml}$ of $\mathrm{n}$-butanol was added. The combined $n$-butanol extracts were washed twice with $10 \mathrm{ml}$ of $5 \%$ aqueous sodium chloride. The remaining solution was heated in a water bath. After evaporation the samples were dried in the oven to a constant weight; the saponin content was calculated as percentage.

\section{Management of experimental chicken}

Broiler chicks were purchased from commercial suppliers and 
used for the experiment at Makerere University Agricultural Research Station, Kabanyolo (MUARIK). During the four weeks while in the brooding room, chicks were vaccinated against Newcastle Disease and Gumboro following recommended veterinary schedule. The chick diets were formulated on site and the ingredients used were maize bran, table salt, cotton seed cake, Vitamin Premix, snail shells and fish (Rastraneobola argentea) which are popular and readily available on the open market in urban areas (Katongole et al., 2011). For consistency of quality, the ingredients were purchased from a single supplier and samples of the feed ingredients were subjected to nutrient analysis at the Nutrition Laboratory at the College of Veterinary Medicine Animal Resources and Biosecurity, Makerere University. The chick starter diets were composed of maize bran $(55 \%)$, cotton seed cake $(26 \%)$, fish (15\%), shells (3\%), table salt $(0.5 \%)$ and Vitamin Premix $(0.5 \%)$. Further, water was provided ad libitum. From the brooder, fifteen broilers were transferred to each of the 30 pens and started on a diet composed of maize bran (58\%), cotton seed cake $(30 \%)$, fish $(8 \%)$, shells $(3 \%)$, table salt $(0.5 \%)$ and Vitamin premix $(0.5 \%)$. All broilers in each set of three pens were subjected to a single treatment defined by any of the three inclusion levels $(1.1,2.2,4.4 \%)$ of $C$. frutescens provided for any of the three durations $(13,19,24$ days) preceding 60th day of age. The control group received only basal diet.

\section{Measurement of body weight and carcass yield of broilers}

The live body weights of the broilers at 59 days of age were taken after being starved for the previous 12 hours. After weighing, the broilers were slaughtered following a process that involved humane killing by bleeding with a single neck cut after cervical dislocation to reduce pain. After bleeding, the birds were scalded in hot water between 56 and $60^{\circ} \mathrm{C}$ for 45 seconds prior to defeathering and evisceration. Weights were taken for eviscerated carcass and internal organs including, heart, liver, proventriculus, gizzard and intestines.

\section{Statistical data analysis}

Descriptive statistics were generated for body weight and carcass yield parameters using R software (R Core Team, 2019). Further, the effects of inclusion levels on the different parameters were determined using a One -Way Analysis of Variance (ANOVA) approach and the treatment effects different from each other were identified by Tukey's HSD statistical test using R software (R Core Team, 2019). The significance level for all tests was 0.05 .

\section{RESULTS AND DISCUSSION}

\section{Phytochemical composition of $C$. frutescens powder}

The phytochemicals detected in $C$. frutescens powder included alkaloids (6.8\%), saponins (23.5\%), phenols (587.75mg GAE/100g) and flavonoids. Both alkaloids and saponins are known to have antibiotic as well as toxicity and anti-feeding properties (Buchanan et al., 2015). The toxicity and anti-feeding properties of alkaloids and saponins suggest that there is need to identify the inclusion levels for $C$. frutescens in diets that do not induce negative effects in livestock including chicken. Phenolic compounds include flavonoids that act as stimulators of smooth muscle function, antimicrobial, antitoxic, immunologic and hepatoprotective agents (Zhang et al., 2019). However, the presence of flavonoids may not be sufficient to realize positive effects on livestock when plant products are used as feed additives. For instance, use of dried lemon pulp as a chicken feed additive at inclusion levels as low as $2.5 \%$ is not recommended (Basir and Toghyani, 2017; Mandey et al., 2019). The observed overall effects on chickens in this study may be partially attributed to the phytochemical composition of $C$. frutescens.

\section{Effect of $\boldsymbol{C}$. frutescens on body weight and carcass yield of broilers}

\section{Body weight}

Increase in mean body weight of broilers was observed under one nutrition strategy where $2.2 \%$ inclusion level increased mean body weight $(1258 \mathrm{~g}, p=0.03$ ) of broilers by $14 \%$ relative to the control after 19 days of feeding (Table 2). This suggests that $C$. frutescens powder can effectively be used to enhance growth at a dietary inclusion level of $2.2 \%$ for 19 days during the finisher phase of broiler production. This ability to improve growth may be attributed to the presence of phytochemicals such as flavonoids, phenols, saponins and alkaloids that are known to perform multiple biological functions including favoring growth of beneficial bacteria (Enterococcus spp, Lactobacillus spp.) that are positively correlated with weight gain (Oluwafemi et al., 2020; Rashid et al., 2020). Moreover, the ability of $C$. frutescens powder to improve growth at $2.2 \%$ inclusion level makes it comparable to other phytogenic feed additives that have achieved similar effects such as tannins from Quebracho (Marzoni et al., 2020) and coriander (Abou-Elkhair et al., 2014), Further, positive effects on growth have also been reported for several phytogenic feed additives when included at lower levels such as $0.2,0.25,0.5,0.75 \%$, for chicory, Myristica fragrans, turmeric and red pepper extract respectively (Khoobani et al., 2020; Adu et al., 2020; Abou-Elkhair et al., 2014; Islam et al., 2018). It is suggested that chicken farmers on local farm settings should consider adoption of $C$. frutescens powder among the alternative feed additives to promote growth in broiler chickens.

\section{Carcass yield}

Diets with $C$. frutescens affected the mean weight of carcass, gizzard, intestines and proventriculus. Particularly, the mean carcass weight $(786 \mathrm{~g}, \quad p=0.03)$ was increased by $15 \%$ relative to the control when broilers were fed diets with $2.2 \%$ inclusion level of $C$. frutescens for 19 days (Table 2). The same dietary 
Table 1. Mean weight of body, carcass and internal organs of broilers at different dietary inclusion levels of $C$. frutescens powder for 13-day duration.

\begin{tabular}{|c|c|c|c|c|c|c|}
\hline \multirow{2}{*}{ Parameter } & \multicolumn{4}{|c|}{ Inclusion level (\%) } & \multirow{2}{*}{ SEM } & \multirow{2}{*}{$p$} \\
\hline & 0 & 1.1 & 2.2 & 4.4 & & \\
\hline Body weight (g) & 1108 & 1231 & 1164 & 1198 & 22.3 & 0.25 \\
\hline Carcass weight $(\mathrm{g})$ & 682 & 744 & 683 & 732 & 13.9 & 0.25 \\
\hline Heart weight(g) & 5.82 & 6.14 & 5.58 & 5.57 & 0.117 & 0.28 \\
\hline Liver weight (g) & $23.3^{a}$ & 23.4 & 21.5 & $20.7^{b}$ & 0.409 & 0.04 \\
\hline Proventriculus weight (g) & 55.6 & 6.1 & 6.29 & 6.07 & 0.109 & 0.89 \\
\hline Gizzard weight (g) & 29.9 & 30.6 & 27.3 & 29 & 0.519 & 0.136 \\
\hline Intestinal weight(g) & $107^{a}$ & $96.9^{d}$ & $78.8^{b}$ & $87.4^{c}$ & 1.98 & $<0.001$ \\
\hline
\end{tabular}

${ }^{\text {abcd }}$ Means in the same row without common letter are different at $\mathrm{P}<0.05$.

Table 2. Mean weight of body, carcass and internal organs of broilers at different dietary inclusion levels of $C$. frutescens powder for 19 days duration.

\begin{tabular}{|c|c|c|c|c|c|c|}
\hline \multirow{2}{*}{ Parameter } & \multicolumn{4}{|c|}{ Inclusion level (\%) } & \multirow{2}{*}{ SEM } & \multirow{2}{*}{$p$} \\
\hline & 0 & 1.1 & 2.2 & 4.4 & & \\
\hline Body weight (g) & $1108^{a}$ & $1102^{b}$ & $1258^{\mathrm{C}}$ & $1125^{d}$ & 19.8 & 0.01 \\
\hline Carcass weight (g) & $682^{\mathrm{a}}$ & 668 & $786^{\mathrm{b}}$ & 717 & 13.6 & 0.01 \\
\hline Heart weight(g) & 5.82 & 6.05 & 6.18 & 5.89 & 0.128 & 0.746 \\
\hline Liver weight (g) & 23.3 & 23.1 & 23.2 & 22.3 & 0.426 & 0.83 \\
\hline Proventriculus weight (g) & 6.11 & 5.56 & 6.17 & 6.02 & 0.113 & 0.21 \\
\hline Gizzard weight $(\mathrm{g})$ & 29.9 & $28.5^{\mathrm{a}}$ & $33.4^{\mathrm{b}}$ & $29.1^{\mathrm{c}}$ & 0.558 & 0.01 \\
\hline Intestinal weight(g) & $107^{\mathrm{a}}$ & 99.1 & $103^{c}$ & $88.6^{b}$ & 1.82 & 0.002 \\
\hline
\end{tabular}

${ }^{\mathrm{abc}}$ Means in the same row without common letter are different at $\mathrm{P}<0.0$.

Table 3. Mean weight of body, carcass and internal organs of broilers at different dietary inclusion levels of $C$. frutescens powder for 24 days duration

\begin{tabular}{|c|c|c|c|c|c|c|}
\hline \multirow{2}{*}{ Parameter } & \multicolumn{4}{|c|}{ Inclusion level (\%) } & \multirow{2}{*}{ SEM } & \multirow{2}{*}{$p$} \\
\hline & 0 & 1.1 & 2.2 & 4.4 & & \\
\hline Body weight (g) & 1108 & 1218 & 1128 & 1145 & 22.2 & 0.33 \\
\hline Carcass weight (g) & 682 & 679 & 687 & 664 & 12.5 & 0.94 \\
\hline Heart weight(g) & 5.82 & 5.56 & 5.7 & 5.58 & 0.118 & 0.85 \\
\hline Liver weight (g) & 23.3 & 23.1 & 21.6 & 21.7 & 0.379 & 0.24 \\
\hline Proventriculus weight $(\mathrm{g})$ & $6.11^{\mathrm{a}}$ & $5.24^{b}$ & $6.12^{\mathrm{c}}$ & 6.02 & 0.122 & 0.02 \\
\hline Gizzard weight (g) & 29.9 & 29 & 29.6 & 28.1 & 0.585 & 0.45 \\
\hline Intestinal weight(g) & $107^{\mathrm{a}}$ & $92.4^{b}$ & 94.2 & 104 & 2.07 & 0.03 \\
\hline
\end{tabular}

${ }^{a b c}$ Means in the same row without common letter are different at $\mathrm{P}<0.05$.

treatment also increased the mean gizzard weight (33.4g) in comparison to 1.1 and $4.4 \%$ inclusion levels for 19 days (Table 2). However, the mean weights of intestines and proventriculus were reduced by at least one of the dietary treatments (Tables 1 to 3 ). Specifically, the $4.4 \%$ inclusion level decreased the mean intestine weight $(87.4 \mathrm{~g}, p=0.001)$ by $18 \%$ relative to the control after 13 days of feeding (Table 1). For a similar feeding duration, the $2.2 \%$ inclusion level reduced the mean intestine weight $(78.8 \mathrm{~g}, p<0.001)$ by $26 \%$ relative to the control (Table 1 ). Moreover, the mean intestine weight was reduced (103g, $p=0.002$ ) by $17 \%$ relative to the control after a 19 day feeding period with $4.4 \%$ inclusion level of $C$. frutescens (Table 2). Following a 24 day feeding duration, the $1.1 \%$ inclusion level reduced the mean weight of proventriculus $(5.24 \mathrm{~g}$, $p=0.05$ ) by $14 \%$ relative to the control (Table 3 ).

These findings suggest that $C$. frutescens, when 
offered at particular inclusion levels at different durations during the finisher phase, has the potential to negatively affect some gut organs of broilers. Interestingly, the mean weight of the heart and liver were not affected and this makes $C$. frutescens appear to have relatively similar effects on the heart and liver as Capsicum annuum (Islam et al., 2018). In contrast, the effects on proventriculus are apparently different for the two types of Capsicums. Particularly, unlike for $C$. frutescens as observed in this study, no effects on proventriculus weights have been reported in the case of $C$. annuum, (Islam et al., 2018). Besides Capsicums, other phytogenics whose effects on internal organs of chicken have been investigated include Myristica fragrans (Adu et al., 2020), Persicaria odorata (Basit et al., 2020), fenugreek seeds (Hashim et al., 2019), paw paw latex (Haruna and Odunsi, 2018), ginger (Qorbanpour et al., 2018) and garlic (Islam et al., 2018). Positive effects on proventriculus have been reported for garlic when used at $0.75 \%$ whereas no influence on weights of internal organs has been observed for Myrisitca fragrans and Persicraia odorata (Islam et al., 2018; Adu et al., 2020; Basit et al., 2020). In contrast, negative effects have been noted with respect to lowering giblets percentage in the case of fenugreek seeds (Hashim et al., 2019) and hypertrophy of gizzard, liver and intestines associated with paw paw latex (Haruna and Odunsi, 2018). In addition, decrease in gizzard weight was observed when ginger powder was used as feed additive at levels ranging from 0.15 to $0.25 \%$ (Qorbanpour et al., 2018). However, increment in gizzard weight and carcass weight were among the positive effects observed in this study when $C$. frutescens was used at $2.2 \%$ inclusion level for 19 days. The capacity to improve carcass weight has also been reported for other single phytogenics such as bee pollen (Hascik et al., 2019) and C. annuum (Islam et al., 2018). Therefore, this study recommends use of locally available $C$. frutescens powder as a feed additive at $2.2 \%$ inclusion level in finisher diets offered to broilers for 19 days effective the 40th day of age in order to improve body weight and carcass yield.

\section{Conclusion}

1) The phytochemicals detected in $C$. frutescens powder were flavonoids, phenols (588 mg GAE/100g), alkaloids (6.8\%), and saponins (23.5\%).

2) C. frutescens should be used as feed additive at $2.2 \%$ level in diets for broilers aged 40 days for duration of 19 days since this level leads to higher body weight and carcass weight.

\section{CONFLICT OF INTERESTS}

The authors have not declared any conflict of interests.

\section{REFERENCES}

Abou-Elkhair R, Ahmed HA, Selim S (2014). Effects of black pepper(Piper nigrum), turmeric powder (Curcuma longa) and coriander seeds (Coriander sativum) and their combinations as feed additives on growth performance, carcass traits, some blood parameters and humoral immune response of broiler chickens. Asian Australasian Journal of Animal Science 27(6):847-854.

Adu OA, Gbore FA, Oloruntola DO, Falowo AB, Olarotimi OJ (2020). The effects of Myristica fragrans seed meal and Syzygium aromaticum leaf meal dietary supplementation on growth performance and oxidative status of broiler chicken. Bulletin of the National Research Centre 44(1):1-10.

Basir R, Toghyani M (2017). Effect of dietary graded levels of dried lemon (Citrus aurantifulia) pulp on performance, intestinal morphology, and humoral immunity in broiler chickens. International Journal of Recycling Organic Waste Agriculture 6:125-132.

Basit MA, Kadir AA, Loh TC, Abdul Aziz S, Salleh A, Zakaria ZA, Banke Idris S (2020). Comparative Efficacy of Selected Phytobiotics with Halquinol and Tetracycline on Gut Morphology, Ileal Digestibility, Cecal Microbiota Composition and Growth Performance in Broiler Chickens. Animals 10(11):2150.

Borgohain B, Mahanta JD, Islam R, Sapcota D, Sarma S, Borah MC (2017). Effect of feeding garlic (Allium sativum) as prebiotic on the performance of broiler chicken. International Journal of Livestock Research 7(7):225-233.

Brand-Willias W, Cuvelier ME, Berset C (1995). Use of a free radical method to evaluate antioxidant activity. LWT-Food Science Technology 28:25-30.

Buchana B, Gruissem W, Jones R (2015). Biochemistry and Molecular Biology of Plants. $2^{\text {nd }}$ Edition. American Society of Plant Physiologists.

Food and Agriculture Organization (FAO) (2019). The future of livestock in Uganda. Opportunities and challenges in the face of uncertainty. Rome

Gaddet U, Kim WH, Oh ST, Lillehoj HS (2017). Alternatives to antibiotics for maximizing growth performance and feed efficiency in poultry: a review. Animal Health Research Reviews 18(1):26-45.

Haruna MA, Odunsi AA (2018). Growth performance and carcass quality of broiler chickens fed dried pawpaw (Carica papaya Linn) latex. Journal of World's Poultry Research 8(2):31-36.

Hascik P, Pavelkova A, Arpasova H, Cubon J, Kacaniova M, Kunova $S$ (2019). The effect of bee products and probiotic on meat performance of broiler chickens. Journal of Microbiology, Biotechnology and Food Sciences 9(1):88-92.

Hashim MKM, El-Shinawy MZ, Mahrous MY, Galal A (2019). Impact of growth promoters addition on productive performance and immune response in broiler chickens. Arab Universities Journal of Agricultural Sciences 27(5):2631-2640.

Islam MA, Haque ME, Shikhauu MSA, Uddin MJ, Uddin MN, Islam MT, Islam MS (2018). Effect of red chili and garlic nutrition as feed additives on growth performance of broiler chicken. International Journal of Natural and Social Sciences 5(3):16-24.

Katongole CB, Sabiiti E, Bareeba F, Ledin I (2011). Utilization of market crop wastes as livestock feed in urban and peri-urban livestock production in Uganda. Journal of Sustainable Agriculture. Available at: https://doi.org/10.1080/10440046.2011.554318

Khoobani M, Hasheminezhad S, Javandel F, Nosrati M, Seidavi A, Kadim IT, Laudadio V, Tufarelli V (2020). Effects of dietary chicory (Chicorium intybus L.) and probiotic blend as natural feed additives on performance traits, blood biochemistry, and gut microbiota of broiler chickens. Antibiotics. Available at: https://doi.org/10.3390/antibiotics9010005

Lillehoj H, Liu Y, Calsamiglia S, Fernandez-Miyakawa ME, Chi F, Cravens RL, Oh S, Gay CG (2018). Phytochemicals as antibiotic alternatives to promote growth and enhance host health. Veterinary Research. Available at: https://doi.org/10.1186/s13567-018-0562-6

Mahanta JD, Borgohain B, Sarma M, Sapcota D, Hussain J (2017). Effect of dietary supplementation of herbal growth promoter on performance of commercial broiler chicken. Indian Journal Animal Research 51(6):1097-1100.

Mandey JS, Wolayan FR, Pontoh CJ, Kowel YHS (2019). Nutrient and 
bioactive potentials of clove and carrot as natural feed additive/water additive candidates for organic broiler chicken. IOP Conference Series: Earth and Environmental Science 387(1):012126.

Marzoni M, Castillo A, Franzoni A, Nery J, Fortina R, Romboli I, Schiavone A (2020). Effects of dietary Quebracho tannin on performance traits and parasite load in an Italian slow-growing chicken (White Livorno breed). Animals 10(4):684. Available at: https://doi.org/10.3390/ani10040684

Muaz K, Riaz M, Akhtar S, Park A, Ismail A (2018). Antibiotic Residues in Chicken meat: Global Prevalence, Threats, and Decontamination Strategies: A Review. Journal of Food Protection 18(4):619-627.

Oluwafem RA, Olawale IA, Alagbe JO (2020). Recent trends in the utilization of medicinal plants as growth promoters in poultry nutrition- a review. Agricultural and Veterinary Sciences 4(1):5-11.

Park JH, Kang SN, Shin D, Shim KS (2015). Antioxidant Enzyme Activity and Meat Quality of Meat Type Ducks Fed with Dried Oregano (Origanum vulgare L.) Powder. Asian Australasian Journal of Animal Science 28(1):79-85.

Puvaca N, Ljubojevic D, Kostadninovic LJ, Levic J, Nikolova N, Miscevic B, Konyves T, Lukac D, Popovic S (2015). Spices and herbs in broilers nutrition: hot red pepper (Capsicum annuum L.) and its mode of action. World's Poultry Science Journal. Available at: https://doi.org/10.1017/S0043933915002214

Qorbanpour M, Fahim T, Javandel F, Nosrati M, Paz E, Seidavi A, Ragni M, Laudadio V, Tufarelli V (2018). Effect of dietary ginger (Zingiber officinale Roscoe) and multi-strain probiotic on growth and carcass traits, blood chemistry, immune responses and intestinal microflora in broiler chickens. Animals. Available at: https://doi.org/10.3390/ani8070117

R Core Team (2019). R: A language and environment for statistical computing. R Foundation for Statistical Computing, Vienna, Austria.
Raffia R, Bashir AG, Seema A, Azra NK, Akbar M (2010). Phytochemical screening of Prunella vulgaris L.-an important medicinal plant of Kashmir. Pakistan Journal of Pharmacological Science 23(4):399-402.

Rashid Z, Mirani ZA, Zehra S, Gilan HMS, Ashraf A, Azhar A, AlGhanim KA, Al-Misned F, Al-Mulahim N, Mahboob S, Galani S (2020). Enhanced modulation of gut microbial dynamics affecting body weight in birds triggered by natural growth promoters administered in conventional feed. Saudi Journal of Biological Sciences 27(10):2747-2755. Available at: https://doi.org/10.1016/j.sjbs.2020.06.027

Roth N, Kasbohrer A, Mayrhofer S, Zitz U, Hofacre C, Domig K J (2019). The application of antibiotics in broiler production and the resulting antibiotic resistance in Escherichia coli: A global review. Poultry Science 98:1791-1804.

Zhang D, Gan R, Farha AK, Kim G, Yang Q, Shi X, Shi C, Luo Q, Xu $\mathrm{X}$, Li H, Corke H (2019). Discovery of antibacterial dietary spices that target antibiotic-resistant bacteria. Microorganisms 7(6):157. Available at: https://doi.org/10.3390/microorganisms7060157 